\title{
OS MECANISMOS RELACIONAIS
}

\section{Eduardo Marques}

Em um sentido abstrato, a discussão sobre mecanismos relacionais confunde-se com a própria análise da política, visto que o poder tem uma natureza intrinsecamente relacional. Entretanto, a maior parte das linhas de análise da política historicamente buscou elementos explicativos localizados em duas escalas opostas de abstração - de um lado, nas estruturas e nos sistemas sociais e, do outro, nos indivíduos e nos processos de decisão individual -, mesmo que pensadas estrategicamente. Apesar disso, a maioria dessas análises incluiu e levou em conta as relações, embora de maneira contextual e metafórica.

A partir dos anos de 1970, entretanto, desenvolveu-se um programa de pesquisas focado no nível intermediário e concentrado na análise dos padrões de relações de indivíduos e entidades que cercam as situações sociais - a sociologia relacional. Esses padrões de relação estariam presentes em praticamente todas as situações sociais, sendo muito difícil estudar fenômenos sociais sem consi- derá-los, como no caso dos fenômenos econômicos, por exemplo (Granovetter, 1985). Concretamente, essa análise reproduz, por meio de representações gráficas e matemáticas, os contextos relacionais dos mais variados tipos, onde se inserem os atores sociais. Nas análises desse tipo, pessoas, grupos, organizações e entidades são representadas como nós, e as relações, como vínculos de vários tipos. Os vínculos podem ser materiais e imateriais, apresentar conteúdos múltiplos e usualmente são pensados como em constante transformação. Na verdade, tais análises tentam sempre reproduzir dedutivamente por meio das redes certas estruturas relacionais de médio alcance, construindo um nível analítico intermediário entre estrutura e ação social. A tarefa é similar à estabelecida com o espaço, pelos sociólogos urbanos marxistas nos anos de 1970, ou com as instituições, pelos neoinstitucionalistas nos anos de 1980.

As redes podem ser entendidas, basicamente, de três formas. Seguindo diversas tra- 
dições das ciências sociais, podemos considerálas apenas de maneira metafórica ou de forma descritiva e ensaística. São definidas também como prescrição normativa para uma determinada situação, como em estudos em administração de empresas, por exemplo. Por fim, são consideradas um conjunto de ferramentas analíticas para o estudo de situações sociais específicas por meio da análise das conexões sociais nelas presentes. Concentro-me neste texto nessa última acepção, pois acredito que os avanços na área advêm da utilização das redes como método de investigação a análise de redes sociais -, uma vez. Os ganhos analíticos do uso do método advêm do fato de que os padrões de relação de diversas situações sociais apresentam complexidade tão elevada que não podem ser analisados satisfatoriamente por meio de narrativas que explorem metaforicamente as redes. Em fenômenos com baixa complexidade, evidentemente, o uso de metáforas pode permanecer como a melhor estratégia, e a análise de redes talvez apenas adicione novos aspectos técnicos e conceituais desnecessariamente.

Como a ciência política enfoca centralmente o poder político (institucionalizado ou não), e como este apresenta uma natureza relacional intrínseca, o estudo das redes sociais pode ajudar bastante. As análises envolvem, por exemplo, o estudo da influência dos padrões de relacionamento em mobilizações coletivas, seja em trabalhos de corte mais tradicional (Gould, 1991), seja em trabalhos mais contemporâneos centrados nas dimensões discursivas da ação política (Mische e White, 1998). De forma similar, a literatura investigou as influências das redes no comportamento eleitoral (Niuwbeerta e Flap, 2000) e na estruturação dos partidos políticos (Hedstrom et. al., 2000). Os estudos sobre as elites políticas também representam um importante campo para a análise das redes, seja do ponto de vista das relações internas à elite política (Gill-Mendieta e Schmidt, 1996) e à elite econômica (Minz e Schwartz, 1981; Kadushin, 1995), seja comparando elites políticas e econômicas (Laumann et al., 1992). Um outro conjunto de trabalhos investiga os padrões de relação no interior do Estado, envolvendo burocracias, agências estatais e políticas públicas (Marques, 2000, 2003) e investigando especificamente a produção de políticas (Knoke, 2003;
Laumann e Knoke, 1987). Como a análise de redes permite a realização de estudos detalhados sem o preestabelecimento das fronteiras entre Estado e sociedade, representa também uma importante ferramenta tanto para o estudo de lobby (Heinz et al., 1997) e de novas institucionalidades de governança (Schneider et al., 2003), como para a análise das relações entre público e privado no entorno do Estado (Marques, 2000, 2003).

A análise de redes sociais parte do pressuposto de que as relações sociais constituem a unidade básica da sociedade, ao invés dos atributos dos indivíduos. Nesse sentido, o mundo social seria formado ontologicamente por padrões de relação de vários tipos e intensidades em constante transformação. Nas primeiras sínteses teóricas sobre essa questão, atributos individuais e relações sociais eram vistos, de uma forma reducionista, como elementos em oposição (Emirbayer, 1997). Atualmente, eles são pensados em associação, visto que, em muitas situações sociais, entidades com atributos comuns têm maior probabilidade de estabelecer relações por causa da presença de mecanismos de homofilia (Kadushin, 2004). Ao mesmo tempo, as relações ajudam a construir atributos de vários tipos, sendo muitas vezes difícil estabelecer uma direção causal única.

Embora os autores enfatizem questões diferentes, é possível reconhecer ao menos três tipos de análise. O primeiro investiga os efeitos das posições dos atores e entidades sobre os fenômenos políticos. Essas posições podem potencialmente: a) alterar os resultados; b) influenciar as ações, estratégias, alianças e oposições e c) influir sobre as propensões cognitivas dos atores (inclusive as suas preferências). O segundo tipo de uso analítico das redes foca nos efeitos da estrutura da rede sobre os fenômenos existentes em uma dada situação. Nesse caso, analisam-se a conformação geral de densidades e grupos, e os padrões de contigüidade, conectividade e distância presentes na rede social. Por fim, o terceiro grupo discute os efeitos de modelos diferentes de estrutura sobre tipos de fenômenos. A ênfase, nesse caso, está na comparação entre estruturas de várias redes de um mesmo tipo. De fato, essas três estratégias foram empreendidas a partir da década de 1970, em um caminho de crescente generalização explicativa. 
Como qualquer estrutura, as redes costumam ser duradouras. Isso porque, embora elas se transformem continuamente com a construção ou o rompimento de vínculos, a parcela em transformação tende a ser relativamente pequena comparada ao conjunto dos vínculos. Além disso, estudos recentes sugerem a existência de elementos associados ao comportamento matemático das redes (Watts, 1999), os quais lhes garantiriam sua continuidade, mesmo em contextos de mudanças intensas de vínculos. A combinação desses elementos faz com que as redes apresentem, a um só tempo, dependência da trajetória, sobretudo em relação à estrutura, e tendências constantes de mudança, principalmente em termos localizados.

Embora a complexidade técnica do tema não seja muito grande, esse tipo de análise envolve escolhas que determinam os resultados dos estudos.

A primeira escolha analítica fundamental diz respeito ao tipo de rede a ser estudada. Em todos os casos, as redes podem ser conceituadas para reproduzir os padrões de relação centrados em um ou mais indivíduos ou em contextos mais amplos, que modelam o tecido relacional de uma determinada situação social (as chamadas redes totais). A escolha de redes pessoais ou amplas depende das preocupações analíticas da investigação.

A segunda escolha refere-se aos elementos que compõem as redes - indivíduos, famílias, grupos, organizações etc. Esses agrupamentos institucionais e grupais, por sua vez, conectam-se muitas vezes por meio dos indivíduos que os constituem. As entidades nas redes, portanto, estão sempre submetidas a uma natureza dual entre indivíduos e grupos e organizações (Breiger e Mohr, 2004) e, novamente, a questão se associa intrinsecamente aos pressupostos analíticos envolvidos.

Por outro lado, os vínculos considerados na análise podem envolver elementos materiais, como dinheiro e mercadoria, e imateriais, como informações, afetos e idéias. Eles podem incluir, virtualmente, qualquer coisa, embora a consideração de certos tipos de vínculo possa trazer dificuldades com relação à operacionalização da pesquisa e mesmo à confiabilidade das informações obtidas no campo.

A essa dimensão se soma outra ligada à intensidade dos vínculos. Desde que Granovetter
(1973) demonstrou a importância fundamental dos vínculos fracos para a difusão de informações associadas a emprego, os autores vêm discutindo essa questão, e hoje há um consenso de que ambos os vínculos devem ser considerados, mas em relação a fenômenos distintos. Os fracos geralmente se fazem presentes na veiculação de informações e na construção de coordenação política. Os fortes, em contrapartida, são importantes quando se trata de fenômenos de coesão, comando e relações mais verticalizadas. Mas ambos não são excludentes, podendo ser considerados inclusive na análise de uma mesma situação, como mostraram Carroll e Fennema (2002).

As redes também podem incluir vínculos formais e informais. Na verdade, uma das potencialidades trazidas pela análise de redes diz respeito exatamente à possibilidade de considerarmos esses dois tipos de vínculos de forma conjunta e sistemática. Embora nem toda a literatura trabalhe dessa forma, a incorporação de vínculos informais e não intencionais vem enriquecendo o estudo sobre elites econômicas (Kadushin, 1995) e sobre atores estatais e não estatais na produção de políticas públicas (Marques, 2003). Especificamente a este respeito, a incorporação de vínculos informais e não intencionais (construídos ao longo da formação das comunidades de políticas) parece ser um caminho promissor para o estudo do Estado de forma mais próxima da realidade empírica (Marques, 2006).

A sociologia relacional também não tem pressupostos fortes com relação à racionalidade dos atores, sendo inclusive possível integrá-la com perspectivas da escolha racional e ferramentas da teoria dos jogos. A análise de redes é apenas incompatível com a adoção de princípios estritos de individualismo metodológico. $\mathrm{Na}$ verdade, a ela apenas indica como funciona um dos settings em que os indivíduos estão inseridos, sendo compatível com vários pressupostos de racionalidade. As próprias redes, entretanto, parecem ser o produto de uma conjugação entre ação orientada a fins, acaso, e herança dos padrões de vínculo anteriores. Como os atores individualmente não têm controle sobre a estrutura das redes e sobre as posições dos demais atores, mesmo que ajam racionalmente para construir e desmontar vínculos (e provavelmente o fazem), 
conseguirão influenciar apenas uma parte muito pequena do tecido relacional em que se inserem. Parodiando Marx, é possível dizer que os indivíduos fazem as redes, mas não as fazem como querem.

Todas as dimensões destacadas sugerem que a análise de redes envolve um grau elevado de escolha da parte do analista no que diz respeito à conceituação dos elementos relacionais presentes nas situações estudadas. Essa característica não trás em si nada de problemático, desde que as escolhas sejam apropriadas às perguntas formuladas e se desdobrem em estratégias e instrumentos de pesquisa também apropriados. Dado o grau de detalhe envolvido, entretanto, a análise de redes trabalha sempre com estudos de caso. Como já destacado na apresentação deste dossiê, no uso dessa estratégia de pesquisa, a generalização dos resultados é obtida com as comparações, variando os elementos presentes e investigando detalhadamente a combinação dos fatores causais em cada conjunto de casos. Assim, apenas a realização de muitos estudos comparativos de redes em situações sociais distintas pode, no médio prazo, sugerir quais os tipos de influências que elas provocam, dadas as circunstâncias e os processos presentes. Embora ainda estejamos longe desse momento, avançamos consideravelmente nas últimas três décadas na compreensão das características, do funcionamento e das conseqüências das redes sociais.

\section{BIBLIOGRAFIA}

BREIGER, R. \& MOHR, J. (2004), "La dualidad y la agregación de categorias sociales". Redes, 5 (4).

CARROLL, W. \& FENEMA, M. (2002). "Is there a transnational business community?". International Sociology, 17 (3).

EMIRBAYER, M. (1997), "Manifesto for a relational sociology". American Journal of Socio$\log y, 103$ (2).

GILL-MENDIETA, J. \& SCHMIDT, S. (1996), "The political network in Mexico". Social Networks, 18.
PAREIGOULD, R. (1991), "Multiple networks and mobilization in the Paris Commune, (1871)". American Sociological Review, 56.

GRANOVETTER, M. (1973). "The strenth of weak ties". American Journal of Sociology, 78.

(1985). "Economic action and social structure: the problem of embeddedness". American Journal of Sociology, $91(3)$.

HEDSTROM, P.; SANDELL, R. \& STERN, C. (2000), "Meso-level networks and the diffusion of social movements". American Journal of Sociology, 106 (1).

HEINZ, J.; LAUMMAN, E.; NELSON, R. \& SALISBURY, R. (1997). The hollow core: private interests in national policy making. Cambridge, Harvard University Press.

KADUSHIN, C. (2004), "Introduction to social network theory". Acessado no site http://home.earthlink.net/ ckadushin/T exts/Basic\%20Network\%20Concepts.pdf \#search $=\% 22$ charles\%20kadushin $\% 20 \mathrm{ch}$ apter $\% 201 \% 22$.

KADUSHIN, C. (1995), "Friendship among the French financial elite". American Sociological Review, 60.

KNOKE, D. (2003), "The sociopolitical construction of national policy domains". Acessado no site http://www.soc. umn. edu/ knoke/.

LAUMANN, E. \& KNOKE, D. (1987), The organizational state: social choice in the national policy domains. Madison, University of Wisconsin Press.

LAUMANN, E.; TAM, T.; HEINZ, J.; NELSON, R. \& SALISBURY, R. (1992), "The social organization of the Washington establishment during the first Reagan administration", in G. Moore A. e Whitt (orgs.), Research in politics and society, Tóquio, JAI Press, vol. 4.

MARQUES, E. (2000), Estado e redes sociais: permeabilidade e coesão nas políticas urbanas no Rio de Janeiro. Rio de Janeiro, Revan/Fapesp. 
(2003), Redes sociais, instituições e atores políticos no governo da cidade de São Paulo. São Paulo, Annablume.

. (2006) "Redes sociais e poder no Estado brasileiro: aprendizados a partir de políticas urbanas". Revista Brasileira de Ciências Sociais, 21 (60).

MINTZ, B. \& SCHWARTZ, M. (1981), "Interlocking directorates and interest group formation". Ann. Soc. Review, 46.

MISCHE, A. \& WHITE, H. 1998. "Between conversation and situation: public switching. dynamics across network-domains". Social Research, 65.

NIEUWBEERTA, P. \& FLAP, H. (2000), "Crosscutting social circles and political choice". Social Neworks, 22.

SCHNEIDER, M.; SCHOLZ, J.; LUBELL, M.; MINDRUTA, D. \& EDWARSEN, M. (2003), "Building consensual institutions: networks and the National Estuary Program". American Journal of Political Science, 47 (1).

WATTS, D. (1999), "Networks, dynamics and the small-world phenomenon". American Journal of Sociology, 105 (2). 